\title{
Ekonomik Özgürlüklerin Dış Ticarete Etkisi: 34 OECD Ülkesi İçin Bir Panel Veri Analizi
}

\section{Effects on Foreign Trade of Economic Freedom: A Panel Data Analysis for 34 OECD Countries}

\author{
Öğr. Gör. Dr. Hakan GÜNEŞ (iD)
}

\begin{abstract}
$\ddot{\mathbf{O} z}$
Bireylerin ekonomik faaliyetlerini gerçekleştirirken herhangi bir engelle karşılaşmadığı, piyasa mekanizmasının etkin bir şekilde işlediği ve girişim serbestliğinin bulunduğu ekonomik özgürlükler, önemli bir refah ölçütüdür. Ülkelerin ekonomik özgürlüğü ne kadar çok olursa, dış ticaret hacimleri de o kadar çok olacaktır. Bu çalışmanın amacı, 34 OECD ülkesinde ekonomik özgürlüklerin dış ticaret üzerine etkisini incelemektir. Bu kapsamda, 1996-2017 yıllarına ait veriler panel veri analiziyle test edilmiştir. Serilerde yatay kesit bağımlılığı olduğundan ikinci nesil panel birim kök testleri kullanılmıştır. Çalışmanın sonucuna göre, ekonomik özgürlüklerle dış ticaret arasında uzun dönemli eş bütünleşik bir iliş̧i tespit edilmiştir. Kurulan ARDL modeli de uzun dönemde diş ticaretin ekonomik özgürlükleri etkilediğini, ancak kısa dönemde bir ilişki olmadığını göstermektedir. Uzun dönemde, ihracattaki bir birimlik artış, ekonomik özgürlükleri 0.18 birim azaltırken; ithalattaki bir birimlik artıș ekonomik özgürlükleri 0.47 birim arttırmaktadır.
\end{abstract}

Anahtar Kelimeler: Ekonomik özgürlükler, ihracat, ithalat, ARDL

Makale Türü: Araştırma

\begin{abstract}
The economic freedoms in which individuals do not face barriers while performing economic activities, the market mechanism operates effectively, and the freedom of interference is an important measure of prosperity. The more economic freedom of countries, the more foreign trade volumes will be. The aim of this study is to examine the effect of economic freedoms on foreign trade in 34 OECD countries. In this context, data for 1996-2017 were tested by panel data analysis. Second-generation panel unit root tests were used because of the cross-sectional dependence problem in the series. According to the result of the study, a long-term cointegrated relationship between economic freedoms and foreign trade has been identified. The established ARDL model also shows that in the long-term foreign trade affects economic freedoms, but there is no relationship in the short term. In the long term, 1 unit increase in exports reduced economic freedoms by 0.18 units; 1 unit increase in imports increases economic freedoms by 0.47 units.
\end{abstract}

Keywords: Economic freedom, export, import, ARDL

Paper Type: Research

\footnotetext{
${ }^{1}$ Bartın Üniversitesi, Bartın Meslek Yüksekokulu, hakangunes@bartin.edu.tr.

Atıf için (to cite): Güneş, H. (2020). Ekonomik özgürlüklerin dış ticaret üzerindeki etkisi: 34 OECD ülkesi için bir panel veri analizi. Afyon Kocatepe Üniversitesi Sosyal Bilimler Dergisi, 22(4), 919-933.
} 


\section{Giriş}

Ekonomik özgürlükler, bireylerin iktisadi faaliyetleri engellerle karşılaşmadan serbestçe yapabileceklerini ifade etmektedir. Serbest piyasa ekonomisini benimseyen gelişmiş ülkeler ekonomik olarak daha özgürken, kamunun ağırlığının daha çok olduğu ve ekonomik faaliyetlerin engellerle karşılaştı̆̆ az gelişmiş ya da gelişmekte olan ülkeler ekonomik olarak nispeten daha az özgürdür.

Özgürlükleri siyasi, sivil ve ekonomik özgürlükler gibi kombinezonlara ayırabiliriz. Sayılan bu özgürlüklerden biri gerçekleşmezse, genel olarak özgürlükler de riske girmektedir (Tunçsiper ve Biçen, 2014, s.26). Ekonomik özgürlükler, piyasaların etkin işlemesini sağlamaktadır. Böylece rekabet ortamında piyasaya giriş çıkış serbestliği ve kişisel tercihlerin özgürce yapılabilmesi sağlanacaktır (Altınışık vd., 2011, s.150).

Ekonomik özgürlüklerin ölçülmesi için, Freedom House, Fraser Enstitüsü ve Heritage Foundation indeksi olarak 3 indeks kullanılmaktadır. Heritage Foundation İndeksi özgürlükleri 5 gruba ayırmıştır. Bu endeks, 80-100 arasını "özgür", 0-49,9 arasını ise "özgür değil" ve 6069,9 arasını ise "orta düzeyde özgür" biçiminde tanımlamaktadır. Aynı zamanda 70-79,9 arasını "kısmen özgür" ve 50-59,9 arasını da "kısmen özgür değil" biçiminde tanımlamaktadır. Bir ülke, diğer ülkeye göre ne kadar yüksek puan alıyorsa, ekonomik anlamda daha özgürdür denilebilir.

Bu çalışmanın temel amacı, 34 OECD ülkesinde 1996-2017 dönemine ait yıllık veriler yardımıyla ekonomik özgürlüklerin dış ticarete etkisini incelemektir. Çalışmada öncelikle teorik çerçeve çizilmiş; daha sonra Heritage Found indeksi çerçevesinde ekonomik özgürlüklerin nasıl ölçüleceği belirlenerek ekonomik özgürlüklerin dış ticarete etkisini ele alan literatür taramasına yer verilmiştir. 1996-2017 yıllarına ait 34 OECD ülkesinde ekonomik özgürlükler ile dış ticaret ilişkisi 2.nesil birim köklerle sınanmış ve sonrasında ARDL modeliyle kısa ve uzun dönem ilişkileri belirlenmiştir. Akademik literatürde bu konu ile ilgili yapılan çalışmalar sınırlıdır. Ekonomik özgürlükleri daha çok ekonomik büyüme ile inceleyen çalışmalar yaygındır. Bu çalışma iki değişkeni içerse de, ekonomik özgürlükleri dış ticaret ile incelediğinden dolayı diğer çalışmalardan farklıdır ve bu yönüyle literatüre katkı sağlayacağı düşünülmektedir.

\section{Ekonomik Özgürlüklerin Ölçümü}

Bireylerin ekonomik faaliyetlerini serbestçe geliştirebildiği ve bu faaliyetler sonucu elde edilen değerleri serbestçe kullanabilmeleri ekonomik özgürlük olarak adlandırılmaktadır. Ekonomik özgürlükler, kamunun ekonomideki ağırlığı, paranın istikrarlı olması, ticaretin serbest olması, özel mülkiyet hakkının olması ve işgücü ve kredi piyasasında regülasyonların olmaması gibi temel unsurları barındırmaktadır. Bu özelliklere sahip olan ülkeler serbest piyasa ekonomisini oluşturmaktadır.

Ekonomik özgürlükler, hükümetlerin piyasadaki faaliyetlerini kısıtlamaktadır. Kişisel tercihlerin serbestliği, rekabet özgürlüğü ve piyasaya giriş serbestisi varsa ekonomik özgürlükler de o denli fazladır. Ancak hükümetler yapmış oldukları politikalar ve regülasyonlarla bunu daraltırsa ekonomik özgürlükler azalacaktır (Yenipazarl1, 2009, s.10).

Günümüzde, ekonomik özgürlüklerin ölçümü üzerine çalışan 3 kurum bulunmaktadır. Ölçüm düzeyleri farklı olsa da birbirine yakın sonuçlar bulan bu endeksler Dünya Ekonomik Özgürlüğü Endeksi (EFW-Economic Freedom of The World), Freedom House Index (FWFreedom of the World) ve Ekonomik Özgürlük Endeksi (IEF-Index of Economic Freedom) ismiyle yayınlanmaktadır. IEF, 1995 'den beri Heritage Foundation ve Wall Street Journal ortaklığıyla 10 alt grupta her sene 186 ülke için hazırlanmaktadır (Akıncı vd., 2015, s.149). Heritage Foundation ekonomik özgürlük indeksi Adam Smith'in tanımlamalarına göre oluşturulmuştur (Çetenak ve Işık, 2016, s.2). Heritage Foundation endeksince belirlenen ekonomik özgürlükler, 10 alt gruptan oluşmaktadır. Bu gruplar, iş yapabilme ve işgücü 
serbestliği, ticari, mali, parasal, finansal ve yatırım serbestliği, mülkiyet hakları, kamu harcamaları ve yolsuzlukta muaflık olarak belirlenmektedir (Beheshtitabar ve Irgaliyev, 2008, s. $6)$.

$\mathrm{Bu}$ çalışmada da Heritage Foundation Index tarafından belirlenen "Ekonomik Özgürlük Endeksi (IEF)" kullanılmaktadır. Bu kapsamda bu 3 kuruma ait ekonomik özgürlük göstergeleri Tablo 1'de gösterilmiştir.

Tablo 1. Endekslere göre ekonomik özgürlük göstergeleri

\begin{tabular}{|c|c|c|}
\hline FRASER & FREEDOM HOUSE & HERITAGE FOUNDATION \\
\hline $\begin{array}{l}\text { Paranın Bir Değer ve Değişim } \\
\text { Aracı Olarak Korunması }\end{array}$ & Mülkiyet Özgürlüğü & Uluslararası Ticaret Özgürlüğü \\
\hline $\begin{array}{l}\text {-Para arzı artışının ve enflasyonun } \\
\text { az olması } \\
\text {--Döviz tutabilme serbestliği } \\
\text {-Kendi ülkesinin dışında da hesap } \\
\text { açabilme serbestliği }\end{array}$ & $\begin{array}{l}\text {-Özel ve fikri mülkiyet } \\
\text { sahipliği } \\
\text {-Mülkiyet değişimi } \\
\text { özgürlüğü }\end{array}$ & $\begin{array}{l}\text { - Tarifelerin az olması ve serbest } \\
\text { ticaret }\end{array}$ \\
\hline $\begin{array}{l}\text { Hangi malın üretilip } \\
\text { tüketileceğine karar verme } \\
\text { serbestliği }\end{array}$ & $\begin{array}{l}\text { Hayatını Kazanma } \\
\text { Özgürlüğü }\end{array}$ & $\begin{array}{l}\text { Hayatını Kazanma ve Teşebbüs } \\
\text { Özgürlüğü }\end{array}$ \\
\hline $\begin{array}{l}\text {-Kamu harcamalarının az olması } \\
\text {-Kamusal oluşumların azlığ } \\
\text {-Fiyat ve faizlerde kısıtlama } \\
\text { olmaması } \\
\text {-Piyasada serbestlik } \\
\text {-Mülkiyet haklarını korumak ve } \\
\text { mahkemelerin yansız olması }\end{array}$ & $\begin{array}{l}\text {-Kurumların pazarlık } \\
\text { yapabilme özgürlüğü } \\
\text {-Ücretlerde kontrol olmaması }\end{array}$ & $\begin{array}{l}\text {-Ücret ve fiyatlarda kontrol } \\
\text { olmaması }\end{array}$ \\
\hline Hayatını Kazanma Özgürlüğü & Teşebbüs Özgürlüğü & $\begin{array}{l}\text { Hangi malın üretilip tüketileceğine } \\
\text { karar verme serbestliği }\end{array}$ \\
\hline $\begin{array}{l}\text {-Marjinal vergi oranı, } \\
\text { sübvansiyon ve transferlerin az } \\
\text { olması } \\
\text {-Askerliğin mecburi olmaması }\end{array}$ & $\begin{array}{l}\text {-İstediği işi kurma özgürlüğü } \\
\text {-Piyasada serbestlik } \\
\text {-Fiyatlarda kontrol olmaması }\end{array}$ & $\begin{array}{l}\text {-Kamu harcamaları ve kamu } \\
\text { teşekküllerinin azlığı }\end{array}$ \\
\hline Uluslararası Ticaret Özgürlüğü & $\begin{array}{l}\text { Kazançları Yatırıma } \\
\text { Dönüştürme Özgürlüğü }\end{array}$ & Paranın Değerinin Korunması \\
\hline $\begin{array}{l}\text {-Tarifelerin az olması } \\
\text {-Resmi ve resmi olmayan döviz } \\
\text { kuru arasında fark olmaması } \\
\text {-Sermaye hareketlerinin } \\
\text { serbestliği }\end{array}$ & $\begin{array}{l}\text {-Piyasada kredi tahsisi } \\
\text {-Bağımsız Merkez } \\
\text { Bankasının } \\
\text {-Kâr ve faizlerde kısıtlama } \\
\text { olmaması }\end{array}$ & -Enflasyon oranının düşüklüğü \\
\hline & $\begin{array}{l}\text { Uluslararası Ticaret } \\
\text { Özgürlüğ̈̈ } \\
\text {-Tarifelerin az olması ve } \\
\text { serbest ticaret } \\
\text {-Döviz serbestliği } \\
\text {-Yabancı sermaye için } \\
\text { kısıtlamaların az olması } \\
\end{array}$ & $\begin{array}{l}\text { Sermaye Akışı Konusunda } \\
\text { Özgürlük } \\
\text {-Yabancı sermayenin giriş-çıkışında } \\
\text { sınırlama olmaması } \\
\text {-Yerli-yabancı firma ayrımı } \\
\text { olmaması }\end{array}$ \\
\hline & $\begin{array}{l}\text { Piyasada İş Yapabilme } \\
\text {-Piyasada herhangi bir } \\
\text { ayrımcılık ve yolsuzluk } \\
\text { olmaması }\end{array}$ & $\begin{array}{l}\text { Bankacılık Sisteminde Açıklık } \\
\text {-Yabancı bankaların rahatça } \\
\text { piyasaya girebilmesi } \\
\text {-Bankacılık sisteminde kısıtlı } \\
\text { regülasyonlar }\end{array}$ \\
\hline
\end{tabular}

Kaynak: Hanke ve Walters, 1997, s. 127-128

Heritage Foundation endeksi, ekonomik özgürlükleri 10 kriterle belirlemiştir. Bunlar şu şekilde gösterilebilir:

(1) Ticaret Politikası: Ticaret serbestisi olan ülkeler diğerlerinden daha özgürdür. 
(2) Vergi Politikası: Düşük vergi yüküne sahip ülkeler diğerlerinden daha özgürdür.

(3) Kamu Harcamaları Düzeyi: Kamu harcamalarının GSYİH içindeki payı az olan ülkeler diğerlerinden daha özgürdür.

(4) Para Politikası: Düşük enflasyona sahip ülkeler diğerlerinden daha özgürdür.

(5) Yabancı Sermaye: Yabancı sermaye serbestliği olan ülkeler diğerlerinden daha özgürdür.

(6) Bankacılık: Bankacılıkta kamunun payı ve müdahalesi özgürlüğü belirler. özgürdür.

(7) Ücret ve Fiyat Kontrolleri: Devlet müdahalesi az olan ülkeler diğerlerinden daha

(8) Mülkiyet Hakkı: Bireysel mülkiyetin yasa ve anayasada güvencede olduğu ülkeler diğerlerinden daha özgürdür.

(9) Regülasyonlar: Regülasyon ne kadar azsa özgürlük o kadar çoktur.

(10) Karaborsa: Karaborsa ne kadar çoksa özgürlük o kadar azdır (Aktan, 1997:59-60).

Çalışmada ele alınan Heritage Foundation İndeksi özgürlükleri 5 gruba ayırmıştır. Bu endeks, 80-100 arasını "özgür", 0-49,9 arasını ise "özgür değil" ve 60-69,9 arasını ise "orta düzeyde özgür" biçiminde tanımlamaktadır. Aynı zamanda 70-79,9 arasını "kısmen özgür" ve 50-59,9 arasını da "kısmen özgür değil" biçiminde tanımlamaktadır. Ülkelerin büyük çoğunluğu 60-80 puan arasındadır. Bir ülke, diğer ülkeye göre ne kadar yüksek puan alıyorsa, ekonomik anlamda daha özgürdür denilebilir.

Tablo 2'de çalışmaya konu olan 34 OECD ülkesinde IEF endeksinin 2017 yılına ait ekonomik özgürlük indeks değerleri verilmiştir.

Tablo 2. 34 OECD ülkesi için ekonomik özgürlük puanları (2017)

\begin{tabular}{llllll}
\hline Siralama & Ülke & Puan & Siralama & Ülke & Puan \\
\hline 3 & Yeni & 83,7 & 26 & Almanya & 73,8 \\
& Zelanda & & & & \\
4 & İsviçre & 81,5 & 28 & Çek & 73,3 \\
& & & & Cumhuriyeti & \\
5 & Avustralya & 81 & 30 & Avusturya & 72,3 \\
6 & Estonya & 79,1 & 36 & İsrail & 69,7 \\
7 & Kanada & 78,5 & 40 & Japonya & 69,6 \\
9 & İlanda & 76,7 & 45 & Polonya & 68,3 \\
10 & Şili & 76,5 & 49 & Belçika & 67,8 \\
12 & İngiltere & 76,4 & 56 & Macaristan & 65,8 \\
14 & Lüksemburg & 75,9 & 57 & Slovakya & 65,7 \\
15 & Hollanda & 75,8 & 60 & Türkiye & 65,2 \\
17 & ABD & 75,1 & 69 & İspanya & 63,6 \\
18 & Danimarka & 75,1 & 70 & Meksika & 63,6 \\
19 & İsveç & 74,9 & 72 & Fransa & 63,3 \\
22 & İzlanda & 74,4 & 77 & Portekiz & 62,6 \\
23 & Güney Kore & 74,3 & 79 & İtalya & 62,5 \\
24 & Finlandiya & 74 & 97 & Slovenya & 59,2 \\
25 & Norveç & 74 & 127 & Yunanistan & 55 \\
\hline
\end{tabular}

Kaynak: Miller ve B. Kim, 2017, s.1-2.

Tablo 2'ye göre, çalışmadaki 34 OECD ülkesinin 3'ü (Yeni Zelanda, İsviçre ve Avustralya) özgür ülkelerdir. Diğer 29 ülke ise kısmen ve orta derecede özgür ülkelerdir. 
Türkiye de 65,2 puanla orta derecede özgür bir ülkedir. Çalışmadaki ülkelerden en düşük puanı alan Yunanistan ve Slovenya ise kısmen özgür olmayan ülkelerdir.

Heritage Foundation tarafından hazırlanan 2017 ekonomik özgürlük indeksinde yer alan ilk 10 ve son 10 ülkeler ise Tablo 3'de verilmiştir.

Tablo 3. Heritage Foundation İndeksine göre en çok ve en az puan alan ülkeler

\begin{tabular}{llllll}
\hline \multicolumn{2}{c}{ En Çok Puan Alan İlk 10 Ülke } & \multicolumn{3}{c}{ En Az Puan Alan Son 10 Ülke } \\
\hline Sira & Ülke & Puan & Sira & Ülke & Puan \\
1 & Hong Kong & 89,8 & 171 & Cibuti & 46,7 \\
2 & Singapur & 88,6 & 172 & Cezayir & 46,5 \\
3 & Yeni Zelanda & 83,7 & 173 & Doğu Timor & 46,3 \\
4 & İsviçre & 81,5 & 174 & Ekvatoral Gine & 45 \\
5 & Avustralya & 81 & 175 & Zimbabve & 44 \\
6 & Estonya & 79,1 & 176 & Eritre & 42,2 \\
7 & Kanada & 78,5 & 177 & Kongo Cumhuriyeti & 40 \\
8 & Birleşik Arap Emirlikleri & 76,9 & 178 & Küba & 33,9 \\
9 & İrlanda & 76,7 & 179 & Venezüella & 27 \\
10 & Şili & 76,5 & 180 & Kuzey Kore & 4,9 \\
\hline
\end{tabular}

Kaynak: Miller and B. Kim, 2017, s.1-12.

Tablo 3'e göre, Hong Kong 89,8 puanla en özgür ülkedir. 80 puanın üstünde 5 ülke olduğu için sadece 5 ülke özgür olarak kabul edilmektedir. 29 ülke kısmen özgür; 58 ülke orta derecede özgür ve 66 ülke ise kısmen özgür olmayan ülkelerdir. 2017 verilerinde 180 ülkeden 32'si özgür olmayan ülkelerdir.

\section{Kavramsal Çerçeve ve Literatür Taraması}

Ekonomik özgürlükler ile dış ticaret ilişkisinde temel mantık, tarifelerin düşük olması, ticareti ve yabancı sermaye girişini kontrollerin olmamasıdır. Genelde ticari bakımdan özgür olan ülkeler, kişi başına düşen geliri yüksek olan ve nüfusu az olan ülkelerdir.

Ekonomik özgürlüklerin temel unsurlarından birisi de ticari serbestliktir. Ticari serbestlik, ülkelerdeki dış ticaret serbestliğini ve ülkenin uluslararası sermaye hareketlerine ne denli açık olduğunu gösterir. Ticaret serbestliği için belli göstergeler vardır. Bunlar;

- Dış ticaret üzerindeki vergiler (vergi gelirleri, ortalama tarife oranları ve tarife oranlarının standart sapması),

- Düzenleyici ticaret engelleri (tarife dış1 engeller, ihracat ve ithalat formaliteleri),

- Ticaret sektörünün beklenen hacmine göre fiili hacmi,

- Resmi döviz kuru ile karaborsa kuru arasındaki fark,

- Uluslararası sermaye hareketleri üzerindeki kontroller (yabancı varlık sahipliği ve yatırımlar üzerindeki kısıtlamalar, sermaye kontrolleri) (Acar, 2010, s.13).

Ekonomik özgürlük indeksleri, ticari açıklığı GSYİH'nın önemli bir belirleyicisi olarak görmüşlerdir ve bu yüzden politikacılar yaşam standartlarını yükseltmek için ticari özgürlüğe önem vermişlerdir (Lamaj, 2015, s.1534). Ticari açıklık ve diğer ekonomik özgürlük ölçütleri sadece doğrudan faydaları için değil, aynı zamanda büyüme ve gelişmeyi teşvik eden ekonomik politikaları izlemeye daha genel bir eğilim gösterdikleri için de önemlidir.

Ekonomik özgürlüklerin dış ticarete etkisi literatürde çok fazla çalışılan konulardan biri değildir. Daha çok, ekonomik özgürlükler ekonomik büyüme ile ilişkilendirilmiştir. Ekonomik özgürlüklerin dış ticaretle olan iliş̧kisini ele alan 3 çalışma tespit edilmiştir. Bu çalışmalardan Sonora'nın (2008) çalışmasında, ABD ve ABD ile ihracat ve ithalat yapan 131 ülkede, 20002005 dönemleri için ekonomik özgürlüklerin ihracat ve ithalata etkisini incelemiştir. Çalışmada, 
öncelikle korelasyon analizi ile ilişki test edilmiş, daha sonra havuzlanmış OLS modeli ile katsayı tahmini yapılmıştır. Çalışmanın sonucuna göre, özgürlükler ihracatı ve ithalatı negatif yönde etkilemektedir. Naanwaab ve Diarrassouba (2013) ise çalışmalarında, 33 Afrika ülkesinde 2000-2009 dönemleri için ekonomik özgürlüklerin Afrika içi ikili ticarete etkisini incelemiştir. Panel veri analizi kullanılan bu çalışmanın sonucuna göre, hem ihracatçı hem de ithalatçı ülkelerin ekonomik özgürlügünün ticaret hacmini olumlu yönde etkilemektedir. Çalışmada, ekonomik özgürlükler arttıkça ülkeler arasında daha fazla ticaret yapılacağı belirtilmiştir. Razmi ve Refaei (2013) ise çalışmalarında, 17 Ortadoğu ve Doğu Asya ülkesinde 2000-2009 dönemleri için ticari açıklık, ekonomik özgürlük ve ekonomik büyüme arasındaki ilişkiyi test etmiştir. Statik panel regresyon analizini kullandıkları bu çalışmanın sonucuna göre, ekonomik özgürlüklerin ticari açıklık ve ekonomik büyümeye pozitif bir etkisi vardır.

\section{Veri, Yöntem ve Bulgular}

\subsection{Veri ve Model}

Bu çalışmada, 34 OECD ülkesinde²1996-2017 dönemine ilişkin verilerle ekonomik özgürlüklerin diş ticaret üzerindeki etkisi test edilmiştir. Modelde ekonomik özgürlükler, Heritage Foundation endeksinden elde edilen ekonomik özgürlük endeksi verileridir ve modelde "EOI" olarak ifade edilmektedir. Seriler Dünya Bankası'nın veri tabanı olan "databank.worldbank.org" adresinden temin edilmiştir.

Çalışmada 34 OECD ülkesi için 2 farklı model şu şekilde tanımlanmaktadır:

$$
\mathrm{EXGDP}_{\mathrm{it}}=\alpha_{\mathrm{it}}+\beta 1_{\mathrm{i}} \mathrm{EOI}_{\mathrm{it}}+\varepsilon_{\mathrm{it}}
$$

$$
\operatorname{IMGDP}_{\mathrm{it}}=\alpha_{\mathrm{it}}+\beta 1_{\mathrm{i}} \mathrm{EOI}_{\mathrm{it}}+\varepsilon_{\mathrm{it}}
$$

Burada; EOI; Heritage Foundation tarafından verilen ekonomik özgürlük endeksini, EXGDP; ihracatın GSYIH'ya oranını ve IMGDP ise ithalatın GSYIH'ya oranın göstermektedir.

$\mathrm{Bu}$ çalışmada ekonomik özgürlüklerin ihracat ve ithalat arasındaki uzun dönem ilişkisi ile bu değişkenlerin birbiriyle ilişkisi test edilmiştir. Modelde bağımlı değişken ekonomik özgürlükler, bağımsız değişken ise ihracat ve ithalattır. Bu doğrultuda serilerin durağanlığ 2.kuşak birim kök testleriyle analiz edilerek ARDL modeli kurulmuştur.

\subsection{Ekonometrik Yöntem ve Bulguların Değerlendirilmesi}

Seriler arasında yatay kesit bağımlılı̆̆ 1 varsa ve bu sonuçlar dikkate alınmadan analizler yapılırsa, bulunan sonuçlar hatalı ve tutarsız olacaktır. Bu yüzden serilerde yatay kesit bağımlılığı olup olmadığı test edilmektedir (Menyah et.al., 2014, s. 839). Olasılık değerleri \%5'den küçükse birimler arasında yatay kesit bağımlılığı olduğu kanısına varılmaktadır (Pesaran ve Yamagata, 2008:17).

Yatay kesit bağımlılığının tespiti için geliştirilen ilk test Breush-Pagan (1980) $\mathrm{CD}_{\mathrm{LM}}$ testidir. Sonrasında ise Pesaran (2004) CD testi ve Pesaran vd. (2008) Düzeltilmiş LM testleri geliştirilmiştir. Zaman boyutu büyük ve kesit boyutu küçük olduğunda $(\mathrm{T}>\mathrm{N})$ Breush-Pagan (1980) $C_{\text {LM }}$ testi; T ve N birbirine yakınsa ya da N>T ise Pesaran (2004) CD testi ve oluşacak

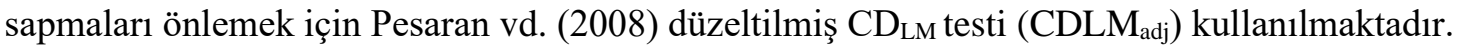

$\mathrm{N}>\mathrm{T}$ olduğu durumlarda, Pesaran (2004) yeni bir CD testi önermektedir. Bu test (3) no'lu eşitlikte gösterilmiştir.

$C D=\sqrt{\frac{2 T}{N(N-1)}} \sum_{i=1}^{N-1} \sum_{j=i+1}^{N}\left(\hat{\rho}_{i j}\right)$

${ }^{2}$ ABD, Almanya, Avustralya, Avusturya, Belçika, Birleşik Krallık, Çekya, Danimarka, Estonya, Finlandiya, Fransa, Güney Kore, Hollanda, İrlanda, İsrail, İ́sveç, İsviçre, İspanya, İtalya, İzlanda, Japonya, Kanada, Lüksemburg, Macaristan, Meksika, Norveç, Polonya, Portekiz, Slovakya, Slovenya, Şili, Türkiye, Yeni Zelanda, Yunanistan. 
Oluşacak sapmaları düzeltmek için ise Pesaran vd. (2008) düzeltilmiş CDLM (CDLMadj) testini geliştirmiş ve (4) no'lu eşitlikte gösterilmiştir.

$C D_{a d j}=\sqrt{\frac{2 T}{N(N-1)}} \sum_{i=1}^{N-1} \sum_{j=i+1}^{N}\left(\hat{\rho}_{i j} \frac{(T-k) \hat{\rho}_{i j}^{2}-u_{T i j}}{\sqrt{v_{T i j}^{2}}}\right)$

Modele eklenen $\boldsymbol{u}_{\boldsymbol{T} i \boldsymbol{j}}$ and $\boldsymbol{v}_{\boldsymbol{T} i \boldsymbol{j}}^{2}$ yeni eklenen ortalamaları, $(\boldsymbol{T}-\boldsymbol{k}) \widehat{\boldsymbol{\rho}}_{\boldsymbol{i j}}^{2}$ ise varyans1 göstermektedir.

Tablo 4'de değişkenler için yatay kesit bağımlılığı testi yer almaktadır.

Tablo 4. Değişkenler için yatay kesit bağımlılığı testi

\begin{tabular}{|c|c|c|c|c|}
\hline & \multicolumn{2}{|c|}{ CD Test } & Test İs. & Ol. \\
\hline \multirow[t]{4}{*}{ EOI } & $\mathrm{CD}_{\mathrm{LM} 1}$ & & 3175.704 & 0.0000 \\
\hline & $\mathrm{CD}_{\mathrm{LM} 2}$ & & 77.04453 & 0.0000 \\
\hline & $\mathrm{CD}_{\mathrm{LM} 3}$ & & 33.87996 & 0.0000 \\
\hline & $\begin{array}{l}\text { Bias-corrected } \\
\text { LM }\end{array}$ & scaled & 76.23501 & 0.0000 \\
\hline \multirow[t]{4}{*}{ EXGDP } & $\mathrm{CD}_{\mathrm{LM} 1}$ & & 5271.001 & 0.0000 \\
\hline & $\mathrm{CD}_{\mathrm{LM} 2}$ & & 139.5977 & 0.0000 \\
\hline & $\mathrm{CD}_{\text {LM3 }}$ & & 50.11654 & 0.0000 \\
\hline & $\begin{array}{l}\text { Bias-corrected } \\
\text { LM }\end{array}$ & scaled & 138.7881 & 0.0000 \\
\hline \multirow[t]{4}{*}{ LOGCO2 } & $\mathrm{CD}_{\mathrm{LM} 1}$ & & 5675.028 & 0.0000 \\
\hline & $\mathrm{CD}_{\mathrm{LM} 2}$ & & 151.6595 & 0.0000 \\
\hline & $\mathrm{CD}_{\mathrm{LM} 3}$ & & 56.48181 & 0.0000 \\
\hline & $\begin{array}{l}\text { Bias-corrected } \\
\text { LM }\end{array}$ & scaled & 150.8500 & 0.0000 \\
\hline
\end{tabular}

Tablo 4'e göre tüm CDLM testlerinin olasılık değerleri \%5'ten küçük olduğundan ekonomik özgürlükler, ihracat ve ithalat değişkenleri için yatay kesit bağımlılığ 1 olduğu tespit edilmiştir. Bu sonuçlara göre ülkelerin birinin ekonomik özgürlüklerine ya da dış ticaretlerine gelen bir şok, diğer ülkelerin de ilgili göstergelerini etkilemektedir.

Serilerde yatay kesit bağımlılığ varsa ikincil nesil panel birim kök testleri kullanılmalıdır. $\mathrm{N}>\mathrm{T}$ ve $\mathrm{T}>\mathrm{N}$ gibi durumlarda CADF testi uygulanabilmektedir (Pesaran, 2007, s.269). Bu çalışmada da yatay kesit bağımlılı̆̆ bulunduğundan dolayı, ikincil nesil panel birim kök testi kullanılmıştır. Tablo 5'de CADF birim kök testi sonuçları verilmiştir.

Tablo 5. CADF birim kök testi sonuçları

\begin{tabular}{|c|c|c|c|c|c|c|c|}
\hline $\begin{array}{l}\text { Değişkenler/ } \\
\text { Ülkeler }\end{array}$ & $\begin{array}{l}\text { EOI-test } \\
\text { (düzey) }\end{array}$ & is. & $\begin{array}{l}\text { EXGDP-test } \\
\text { (düzey) }\end{array}$ & is. & $\begin{array}{l}\text { EXGDP- test } \\
\text { (1.fark) }\end{array}$ & is. & $\begin{array}{l}\text { IMGDP- test is. } \\
\text { (düzey) }\end{array}$ \\
\hline AUST & -1.3414 & & -2.2889 & & -3.8495 & & -1.6732 \\
\hline BELG & -1.5984 & & -1.2778 & & -4.5693 & & -1.1087 \\
\hline CAN & -2.5205 & & -0.9179 & & -3.1297 & & -1.5449 \\
\hline DENM & -1.6613 & & -1.6871 & & -3.7524 & & -1.5994 \\
\hline FRAN & -1.0099 & & -1.5410 & & -3.7024 & & -1.6049 \\
\hline GERM & -1.0775 & & -2.0247 & & -3.4172 & & -1.8033 \\
\hline GREE & -1.0723 & & -1.1324 & & -3.6907 & & -3.7330 \\
\hline ICEL & -2.3216 & & -1.5437 & & -2.2231 & & -1.9555 \\
\hline IREL & -1.7531 & & -1.1511 & & -2.4872 & & -1.3892 \\
\hline ITAL & -3.2647 & & -0.9353 & & -4.0379 & & -2.1432 \\
\hline LUXE & -2.6196 & & -1.0938 & & -3.0820 & & -1.1552 \\
\hline NETH & -1.6801 & & -0.5915 & & -3.6913 & & -0.5794 \\
\hline NORW & -1.0052 & & -1.9725 & & -4.7142 & & -2.1250 \\
\hline PORT & -2.5372 & & -0.0052 & & -3.3421 & & -1.9172 \\
\hline SPAI & -3.2745 & & -0.6535 & & -3.1530 & & -3.2928 \\
\hline
\end{tabular}




\begin{tabular}{|c|c|c|c|c|c|c|c|c|}
\hline SWED & -1.7752 & & -2.2352 & & -3.5315 & & -2.2150 & \\
\hline SWIT & -1.4423 & & -1.1842 & & -4.1938 & & -1.2291 & \\
\hline TURK & -1.2832 & & -3.9141 & & -5.2314 & & -2.7218 & \\
\hline UNKIN & -2.0800 & & -0.6493 & & -3.3024 & & -0.9952 & \\
\hline USA & -1.3663 & & -1.1606 & & -2.9269 & & -1.9499 & \\
\hline AUSTR & -1.3030 & & -2.7137 & & -4.2789 & & -3.8294 & \\
\hline CZEC & -0.0620 & & -1.2462 & & -4.0396 & & -1.1078 & \\
\hline FINL & -1.6838 & & -2.4350 & & -3.3373 & & -1.3655 & \\
\hline HUNG & -4.1326 & & -1.5840 & & -3.3697 & & -2.6123 & \\
\hline JAP & -2.0672 & & -1.2748 & & -3.4777 & & -1.2262 & \\
\hline MEX & -2.5956 & & -0.5255 & & -3.7497 & & -0.5810 & \\
\hline NEWZ & -2.5388 & & -1.4339 & & -2.4363 & & -1.5773 & \\
\hline POL & -1.1338 & & -0.9133 & & -4.5517 & & -1.7557 & \\
\hline SLVK & -1.5253 & & -0.7614 & & -4.6789 & & -0.9764 & \\
\hline SKORE & 0.0040 & & -1.9192 & & -4.4321 & & -1.3816 & \\
\hline CHILE & -1.5127 & & -1.6491 & & -2.4299 & & -2.0919 & \\
\hline ESTON & -3.0000 & & -1.4002 & & -3.3226 & & -3.0990 & \\
\hline SLVN & -3.3162 & & -0.4803 & & -4.1463 & & -1.1765 & \\
\hline ISRA & -2.3290 & & -2.1328 & & -2.9622 & & -1.2962 & \\
\hline IPS & İs. & Ol. & İs. & Ol. & İs. & Ol. & İs. & Ol. \\
\hline \multirow[t]{2}{*}{ istatistiği } & - & 0.0135 & 0.55847 & 0.7117 & - & 0.0000 & - & 0.0483 \\
\hline & 2.2117 & & & & 12.7373 & & 1.6618 & \\
\hline
\end{tabular}

Not: Gecikme uzunluğu SIC kriterine göre belirlenmiştir ve toplam gözlem sayısı 680 (1.farkında 646)'dir.

Tablo 5'deki CADF birim kök testine göre, ekonomik özgürlük ve ithalat verisi seviyesinde durağanken, ihracat verisi 1.farkında durağandır. Seriler farklı dereceden durağan olduğu için ARDL modeli kullanılacaktır. ARDL modeline geçmeden önce, uygun gecikme düzeyi belirlenmelidir. Tablo 6'da uygun gecikme uzunluğu belirlenmiştir.

Tablo 6. Uygun gecikme uzunluğu

\begin{tabular}{lllllll}
\hline Lag & LogL & LR & FPE & AIC & SC & HQ \\
\hline 0 & 390.5886 & - & 3.94 & -1.6285 & -1.6022 & -1.6182 \\
1 & 2579.559 & 4341.152 & 4.14 & -10.788 & $-10.683^{*}$ & $-10.746^{*}$ \\
2 & 2591.769 & 24.06 & 4.09 & -10.8015 & -10.617 & -10.729 \\
3 & 2600.782 & 17.647 & 4.09 & -10.8016 & -10.539 & -10.698 \\
4 & 2622.534 & 42.317 & 3.87 & -10.855 & -10.513 & -10.72 \\
5 & 2635.655 & 25.359 & 3.81 & -10.8725 & -10.452 & -10.707 \\
6 & 2646.830 & 21.456 & 3.77 & -10.881 & -10.382 & -10.685 \\
7 & 2654.384 & 14.409 & 3.80 & -10.875 & -10.298 & -10.648 \\
8 & 2668.448 & $26.651^{*}$ & $3.72^{*}$ & $-10.896^{*}$ & -10.240 & -10.638 \\
\hline
\end{tabular}

Tablo 6'da görüldüğü üzere, LR, FPE, AIC, SC ve HQ bilgi kriterleri uygun gecikme uzunluğunu 8 olarak göstermiştir. Nedensellik testleri uygulanmadan önce en büyük durağanlık seviyesi kadar gecikme eklenmelidir. Tablo 7'de ARDL modelinin kısa ve uzun dönem sonuçları yer almaktadır.

Tablo 7. ARDL kısa ve uzun dönem sonuçları

\begin{tabular}{|c|c|c|c|}
\hline \multicolumn{4}{|c|}{ Bağımlı Deği.: LOGEOI } \\
\hline $\begin{array}{l}\text { Deği. } \\
\text { UZUN DÖNEM }\end{array}$ & Kats. & t-is. & Ol. De. \\
\hline LOGEXGDP & -0.189690 & -5.079282 & 0.0000 \\
\hline LOGIMGDP & 0.472836 & 9.641106 & 0.0000 \\
\hline \multicolumn{4}{|l|}{ KISA DÖNEM } \\
\hline CointEq $(-1)$ & -0.266900 & -6.532196 & 0.0000 \\
\hline D(LOGEXGDP) & 0.066985 & 0.951616 & 0.3417 \\
\hline D(LOGIMGDP) & -0.064264 & -1.795864 & 0.0730 \\
\hline $\mathrm{C}$ & 0.847753 & 6.781833 & 0.0000 \\
\hline
\end{tabular}


Tablo 7'deki katsayılar, kısa ve uzun dönem katsayıları ile sistemin kısa vadede dengeye ulaşacağını göstermektedir. Hata düzeltme katsayısı yaklaşık -0.26 ' dır ve anlamlıdır. Uzun dönem katsayıları incelendiğinde ihracatın katsayısı yaklaşık -0.18 çıkmaktadır. Buna göre ihracattaki 1 birimlik artış ekonomik özgürlükleri uzun dönemde 0.18 azaltmaktadır. İthalattaki 1 birimlik artış ise uzun dönemde ekonomik özgürlükleri 0.47 birim arttırmaktadır. Kısa dönem katsayıları incelendiğinde ise ihracat ve ithalattaki değişmenin ekonomik özgürlükleri etkilemediği görülmektedir. Ancak \%10 anlamlılık düzeyi esas alınırsa, ithalattaki 1 birimlik artış ekonomik özgürlükleri 0.06 birim azaltmaktadır.

ARDL modelini panelin tamamı için değil de ülkeler için ayrı ayrı incelediğimizde farklı sonuçlar çıkmaktadır. Tablo 8'de Türkiye için ARDL modeli sonuçları verilmiştir.

Tablo 8. Türkiye için ARDL modelinin sonuçları

\begin{tabular}{llll}
\hline Bağımlı Deği.: LOGEOI & & \\
\hline Deği. & Kats. & t-is. & Ol. De. \\
CointEq (-1) & -0.283977 & -22.02686 & 0.0002 \\
D(LOGEXGDP) & 0.104706 & 11.10406 & 0.0016 \\
D(LOGIMGDP) & -0.008318 & -1.017433 & 0.3839 \\
C & 0.899725 & 6.982568 & 0.0060 \\
\hline
\end{tabular}

Tablo 8'e göre, hata düzeltme katsayıs1 - 0.28 'dir ve kısa dönemde sistemin dengeye gelişini gösteren bu katsayı anlamlıdır. Tablo 8'e göre, ihracattan ekonomik özgürlüklere doğru tek taraflı bir nedensellik vardır. Türkiye için ithalatla ekonomik özgürlükler arasında ise herhangi bir nedensellik tespit edilememiştir. Bu sonucun nedeni, Türkiye'nin ithalatında hammaddenin büyük rol oynaması şeklinde açılanabilir. Çalışmaya konu olan diğer ülkelere ait ARDL modeli sonuçları EK.1'de verilmiş̧tir.

\section{Sonuç ve Öneriler}

Bu çalışmanın amacı, 34 OECD ülkesinde, ekonomik özgürlüklerin dış ticarete etkisini panel veri analiziyle incelemektir. Bu kapsamda öncelikle ekonomik özgürlük kavramı ele alınarak, ekonomik özgürlüklerin dış ticaret potansiyelini arttırıp artırmayacağı ele alınmıştır. Ekonomik faaliyetlerin kısıtlamalar olmadan serbestçe gerçekleştirildiği, piyasa mekanizmasının etkince işlediği, mülkiyet hakkı ve hukuk kurallarının işlediği bir kuramı ifade eden ekonomik özgürlükler, ülkelerin ekonomik yapıları ve refah ölçütleri hakkında bilgi sunmaktadır. Ekonomik olarak daha özgür ülkeler, yabancı yatırımcıyı daha çok kendisine çekerek sürdürülebilir bir ekonomik büyüme sağlayacaktır. Ekonomik özgürlükler ölçülürken, Fraser Institue, Freedom House ve Heritage Foundation olarak 3 indeks mevcuttur. Bu çalışmada ABD merkezli Heritage Foundation indeksi kullanılmıştır. Heritage Foundation indeksi ülkeleri 0-100 arasında puanlamalara ayırmışıır. Buna göre, 50 puanın altı özgür değilken, 80-100 puan arası özgür ülke durumundadır. Çalışmaya konu olan 34 OECD ülkesinin 3'ü (Yeni Zelanda, İsviçre ve Avustralya) özgür ülke; 2'si (Yunanistan ve Slovenya) kısmen özgür olmayan ülke ve Türkiye'nin de dâhil olduğu diğer 29 ülke de orta derecede özgür ülkelerdir.

$\mathrm{Bu}$ çalışmada ekonomik özgürlüklerin dış ticarete etkisi ele alınmıştır. 34 OECD ülkesi için 1996-2017 dönemine ilişkin verilerle analiz edilmiştir. Yatay kesit bağımlılığ tespit edilen seriler, 2.kuşak birim kök testleriyle durağanlaştırılmıştır. Kurulan ARDL modeli de uzun dönemde dış ticaretin ekonomik özgürlükleri etkilediğini, ama kısa dönemde ilişkinin olmadığ görülmektedir. Uzun dönemde, ihracattaki 1 birimlik artış, ekonomik özgürlükleri 0.18 birim azaltırken; ithalattaki 1 birimlik artış ekonomik özgürlükleri 0.47 birim arttırmaktadır. Başka bir deyişle, ülkeler ithalat yaptıkça, dış dünya ile daha çok entegre olmakta ve ekonomik özgürlükleri artmaktadır. Kısa dönem açısından bakıldığında bir ilişki yokken, \%10 anlamlılık düzeyi esas alınırsa, ithalattaki 1 birimlik artışın ekonomik özgürlükleri 0.06 birim azalttığı görülmektedir. 
$\mathrm{Bu}$ çalışmada son olarak, ele alınan ülke grupları için ARDL modeli çerçevesinde katsayı tahminleri yapılmıştır. Ülkeler için ARDL analizinde farklı sonuçlara rastlanmaktadır. Örneğin Türkiye'de ihracat 1 birim artarken, ekonomik özgürlükler 0.1 birim artmakta (Kanada'da 0.1; Almanya'da 0.13 ve Danimarka'da 0.04); ithalattaki 1 birimlik artış ise ekonomik özgürlükleri 0.008 birim (Kanada'da 0.25; Almanya'da 0.24 ve Danimarka'da 0.09) azaltmaktadır. Yapılan ülke analizlerinde dış ticaret ile ekonomik özgürlükler arasında bir nedensellik bulunmuşken; İsveç, İtalya ve Lüksemburg'da ise dış ticaretteki bir değişme ekonomik özgürlükleri etkilememektedir.

Çalışmadan elde edilen sonuçlara paralel olarak, dış ticaretin ekonomik özgürlükleri etkilediği söylenebilmektedir. Dış ticaret hacminin artması sayesinde ülkeler birbirine daha fazla bağımlı olduğu ve daha fazla yaklaştığı için ekonomik özgürlükleri de artacaktır. Dış ticaretteki artış, daha düşük vergi oranlarını, daha düşük enflasyonu, daha düşük kamu harcamalarını, daha düşük devlet kontrollerini ve daha düşük regülasyonlarıyla birlikte gerçekleşecektir. Bunlar da daha yüksek bir ekonomik özgürlük sağlamaktadır. Bu yüzden ülkeler ekonomik açıdan daha özgür olmak isterse, dış ticaret hacimlerini arttırmaya yönelik açı politikalar izlemelidir.

\section{Kaynakça}

Acar, M. (2010), Serbest ticaret, ekonomik özgürlükler ve refah, Bilig, Bahar-2010, 53, 1-28.

Akıncı, M., Erkal, G. ve Yılmaz, Ö. (2015), Ekonomik özgürlükler ve yolsuzluk ilişkisi: Türkiye için bir zaman serisi analiz, HAK-IŞ Uluslararası Emek ve Toplum Dergisi, Cilt: 4, Y11: 4, 8 (2015/1), 144-165.

Aktan, C. C. (1997), Demokrasi ve Piyasa Ekonomisi Yönünden Türkiye Dünyanın Neresinde, Ege Genç İşadamları Derneği, 1996 Raporu, İzmir 1997.

Altınışık, İ.; Çakmak, Y. ve Peker, H.S. (2011), Ekonomik özgürlükler ve refah, Selçuk Üniversitesi Kadınhanı Faik İçil Meslek Yüksekokulu, Sosyal ve Teknik Araştırmalar Dergisi, Y11:1, Say1:1, May1s 2011, 149-156.

Beheshtitabar, E., Irgaliyev, A. (2008), The Impact of Economic Freedom on FDI Inflows to Developing Countries: The Case of the Middle East, Jönköpinginternational Business School Jönköping University.

Breusch, T.S. ve Pagan, A.R. (1980), The lagrange multiplier test and its applications to model specification tests in econometrics. review of economic studies, 47(1), s.239-253.

Çetenak, Ö.Ö. ve Işı, M. (2016), Ekonomik Özgürlükler İle Ekonomik Büyüme Arasındaki Nedensellik İlişkisi: OECD Ülkeleri Üzerine Bir Uygulama, Nevşehir Hacı Bektaş Veli Üniversitesi SBE Dergisi, 6 (1) 2016 s.1-16.

Hanke, S. H. and Walters, S. J.K. (1997). Economic freedom, prosperity, and equality: a survey. Cato Journal, 17(2), s. 117-146.

Lamaj, J. (2015), The impact of international trade and competition market on developing countries, Management, Knowledge and Learning, Joint International Conference 2015, 27 29 May 2015, Bari, Italy.

Menyah, K., Nazlioglu, Ş. ve Wolde-Rufael, Y. (2014), Financial development, trade openness and economic growth in african countries: new insights from a panel causality approach. economic modelling, 37, 386-394. 
Miller, T. and B. Kim, A. (2017), 2017 Index of Economic Freedom, Institute for Economic Freedom, 1-12. $\quad$ Erișim $\quad$ tarihi: $12 \quad$ Kasım 2018. https://www.heritage.org/index/pdf/2017/book/highlights.pdf

Naanwaab, C. ve Diarrassouba, M. (2013), The impact of economic freedom on bilateral trade: a cross-country analysis, Cephas Naanwaab et al | Int.J.Buss.Mgt.Eco.Res., Vol 4(1),2013, s.668-672.

Pesaran, M. H. (2004), General Diagnostic Tests For Cross Section Dependence In Panels. IZA Discussion paper No:1240, Institute of the Study of Labor, August 2004, Bonn, Germany.

Pesaran, M.H. (2007), A simple panel unit root test in the presence of cross-section dependence. Journal of Applied Econometrics, 22, 265-312.

Pesaran, M. H. ve Yamagata, T. (2008), Testing Slope Homogeneity in Large Panels. Journal of Econometrics, 142(1), s.50-93.

Pesaran, M. H., Ullah, A. ve Yamagata, T. (2008), A Bias-Adjusted lm test of error cross section independence. Econometrics Journal, 11(1), s.105-127.

Razmi, M.J. ve Refaei, R. (2013), The effect of trade openness and economic freedom on economic growth: the case of middle east and east asian countries, International Journal of Economics and Financial Issues, Vol.3, No.2, 2013, s.376-385.

Sonora, R.J. (2008), On the impacts of economic freedom on international trade flows: asymmetries and freedom components, FEB-Working Paper Series, Paper No:08-05, s.1-31.

Tunçsiper, B. ve Biçen, Ö.F. (2014), Ekonomik özgürlükler ve ekonomik büyüme arasındaki ilişkinin panel regresyon yöntemiyle incelenmesi, Eskişehir Osmangazi Üniversitesi IIIBF Dergisi, Ağustos 2014, 9(2), s.25- 45.

Yenipazarl1, A. (2009), Ekonomik özgürlükler ve ekonomik büyüme üzerine etkisi: Türkiye üzerine bir zaman serisi analizi, (Yayımlanmamış doktora tezi), T.C. Adnan Menderes Üniversitesi, Sosyal Bilimler Enstitüsü, İktisat Ana Bilim Dalı, Nazilli-Aydın. 
EK. 1

\begin{tabular}{|c|c|c|c|}
\hline \multicolumn{4}{|c|}{ Bağımlı Deği.: LOGEOI-AVUSTURYA } \\
\hline Deği. & Kats. & t-is. & Ol. De. \\
\hline CointEq (-1) & -0.700273 & -23.53450 & 0.0002 \\
\hline D(LOGEXGDP) & -0.424947 & -6.931351 & 0.0062 \\
\hline D(LOGIMGDP) & 0.355805 & 5.524888 & 0.0117 \\
\hline $\mathrm{C}$ & 2.224888 & 7.400834 & 0.0051 \\
\hline \multicolumn{4}{|c|}{ Bağımlı Deği.: LOGEOI-BELÇİKA } \\
\hline Deği. & Kats. & t-is. & Ol. De. \\
\hline CointEq $(-1)$ & -0.050056 & -3.458219 & 0.0407 \\
\hline D(LOGEXGDP) & 0.378761 & 2.523652 & 0.0859 \\
\hline D(LOGIMGDP) & -0.405144 & -4.218402 & 0.0243 \\
\hline $\mathrm{C}$ & 0.153576 & 1.160165 & 0.3299 \\
\hline \multicolumn{4}{|c|}{ Bağımlı Deği.: LOGEOI-KANADA } \\
\hline Deği. & Kats. & t-is. & Ol. De. \\
\hline CointEq $(-1)$ & -0.043916 & -17.21509 & 0.0004 \\
\hline D(LOGEXGDP) & 0.101711 & 10.31510 & 0.0019 \\
\hline D(LOGIMGDP) & -0.255408 & -14.95057 & 0.0006 \\
\hline $\mathrm{C}$ & 0.152651 & 5.386184 & 0.0125 \\
\hline \multicolumn{4}{|c|}{ Bağımlı Deği.: LOGEOI-DANIMARKA } \\
\hline Deği. & Kats. & t-is. & Ol. De. \\
\hline CointEq $(-1)$ & -0.315492 & -20.01656 & 0.0003 \\
\hline D(LOGEXGDP) & 0.046268 & 2.479081 & 0.0893 \\
\hline D(LOGIMGDP) & -0.091753 & -5.834093 & 0.0100 \\
\hline $\mathrm{C}$ & 1.034683 & 6.200267 & 0.0085 \\
\hline \multicolumn{4}{|c|}{ Bağımlı Deği.: LOGEOI-FRANSA } \\
\hline Deği. & Kats. & t-is. & Ol. De. \\
\hline CointEq $(-1)$ & -0.373409 & -29.62984 & 0.0001 \\
\hline D(LOGEXGDP) & -0.394555 & -8.421931 & 0.0035 \\
\hline D(LOGIMGDP) & 0.261815 & 7.255972 & 0.0054 \\
\hline $\mathrm{C}$ & 1.187491 & 9.069091 & 0.0028 \\
\hline \multicolumn{4}{|c|}{ Bağımlı Deği.: LOGEOI-ALMANYA } \\
\hline Deği. & Kats. & t-istatistiği & Ol. De. \\
\hline CointEq (-1) & -0.472359 & -41.82236 & 0.0000 \\
\hline D(LOGEXGDP) & 0.132363 & 11.69121 & 0.0013 \\
\hline D(LOGIMGDP) & -0.241110 & -19.87963 & 0.0003 \\
\hline $\mathrm{C}$ & 1.553270 & 12.22434 & 0.0012 \\
\hline \multicolumn{4}{|c|}{ Bağımlı Deği.: LOGEOI-YUNANISTAN } \\
\hline Deği. & Kats. & t-is. & Ol. De. \\
\hline CointEq $(-1)$ & -0.278807 & -12.20890 & 0.0012 \\
\hline D(LOGEXGDP) & -0.013681 & -1.295867 & 0.2857 \\
\hline D(LOGIMGDP) & 0.061909 & 4.254860 & 0.0238 \\
\hline $\mathrm{C}$ & 0.844629 & 3.985179 & 0.0283 \\
\hline \multicolumn{4}{|c|}{ Bağımlı Deği.: LOGEOI-İZLANDA } \\
\hline Deği. & Kats. & t-is. & Ol. De. \\
\hline CointEq $(-1)$ & -0.313447 & -21.32343 & 0.0002 \\
\hline D(LOGEXGDP) & -0.055805 & -14.49946 & 0.0007 \\
\hline D(LOGIMGDP) & -0.133184 & -25.58584 & 0.0001 \\
\hline $\mathrm{C}$ & 1.016863 & 6.492996 & 0.0074 \\
\hline \multicolumn{4}{|c|}{ Bağımlı Deği.: LOGEOI-İRLANDA } \\
\hline Deği. & Kats. & t-is. & Ol. De. \\
\hline CointEq $(-1)$ & -0.147128 & -19.90911 & 0.0003 \\
\hline D(LOGEXGDP) & -0.062112 & -4.813473 & 0.0171 \\
\hline
\end{tabular}




\begin{tabular}{|c|c|c|c|}
\hline $\begin{array}{c}\text { D(LOGIMGDP) } \\
\mathrm{C}\end{array}$ & $\begin{array}{l}0.032889 \\
0.470522 \\
\end{array}$ & $\begin{array}{l}3.866104 \\
6.324579 \\
\end{array}$ & $\begin{array}{l}0.0306 \\
0.0080 \\
\end{array}$ \\
\hline \multicolumn{4}{|c|}{ Bağımlı Deği.: LOGEOI-İTALYA } \\
\hline Deği. & Kats. & t-is. & Ol. De. \\
\hline CointEq $(-1)$ & -1.138249 & -24.18502 & 0.0002 \\
\hline D(LOGEXGDP) & 2.118422 & 0.181036 & 0.8679 \\
\hline D(LOGIMGDP) & -0.373006 & -0.043947 & 0.9677 \\
\hline $\mathrm{C}$ & 3.519099 & 7.559916 & 0.0048 \\
\hline \multicolumn{4}{|c|}{ Bağımlı Deği.: LOGEOI-LÜKSEMBURG } \\
\hline Deği. & Kats. & t-is. & Ol. De. \\
\hline CointEq (-1) & -0.039772 & -9.172700 & 0.0027 \\
\hline D(LOGEXGDP) & -0.184190 & -1.616014 & 0.2045 \\
\hline D(LOGIMGDP) & 0.139283 & 1.764762 & 0.1758 \\
\hline $\mathrm{C}$ & 0.121082 & 3.167520 & 0.0506 \\
\hline \multicolumn{4}{|c|}{ Bağımlı Deği.: LOGEOI-HOLLANDA } \\
\hline Deği. & Kats. & t-is. & Ol. De. \\
\hline CointEq $(-1)$ & -0.165196 & -17.85979 & 0.0004 \\
\hline D(LOGEXGDP) & 0.058645 & 4.357211 & 0.0223 \\
\hline D(LOGIMGDP) & -0.188145 & -9.261906 & 0.0027 \\
\hline $\mathrm{C}$ & 0.526977 & 5.681979 & 0.0108 \\
\hline \multicolumn{4}{|c|}{ Bağımlı Deği.: LOGEOI-NORVEÇ } \\
\hline Deği. & Kats. & t-is. & Ol. De. \\
\hline CointEq (-1) & -0.241600 & -23.67961 & 0.0002 \\
\hline D(LOGEXGDP) & 0.020309 & 4.238835 & 0.0240 \\
\hline D(LOGIMGDP) & -0.051332 & -4.782964 & 0.0174 \\
\hline $\mathrm{C}$ & 0.809858 & 7.084413 & 0.0058 \\
\hline \multicolumn{4}{|c|}{ Bağımlı Deği.: LOGEOI-PORTEKİZ } \\
\hline Deği. & Kats. & t-is. & Ol. De. \\
\hline CointEq (-1) & -0.380890 & -18.37793 & 0.0004 \\
\hline D(LOGEXGDP) & -0.000738 & -0.120351 & 0.9118 \\
\hline D(LOGIMGDP) & -0.129559 & -18.53696 & 0.0003 \\
\hline $\mathrm{C}$ & 1.182058 & 5.784606 & 0.0103 \\
\hline \multicolumn{4}{|c|}{ Bağımlı Deği.: LOGEOI-İSPANYA } \\
\hline Deği. & Kats. & t-is. & Ol. De. \\
\hline CointEq (-1) & -0.369423 & -31.32739 & 0.0001 \\
\hline D(LOGEXGDP) & 0.123734 & 5.370803 & 0.0126 \\
\hline D(LOGIMGDP) & -0.213027 & -14.08266 & 0.0008 \\
\hline $\mathrm{C}$ & 1.202437 & 9.609291 & 0.0024 \\
\hline \multicolumn{4}{|c|}{ Bağımlı Deği.: LOGEOI-İSVEÇ } \\
\hline Deği. & Kats. & t-is. & Ol. De. \\
\hline CointEq (-1) & -0.248390 & -20.06427 & 0.0003 \\
\hline D(LOGEXGDP) & 0.137564 & 1.535010 & 0.2223 \\
\hline D(LOGIMGDP) & -0.157949 & -2.057231 & 0.1318 \\
\hline $\mathrm{C}$ & 0.811966 & 6.286860 & 0.0081 \\
\hline \multicolumn{4}{|c|}{ Bağımlı Deği.: LOGEOI-İSVİÇRE } \\
\hline Deği. & Kats. & t-is. & Ol. De. \\
\hline CointEq (-1) & -0.199851 & -8.176416 & 0.0038 \\
\hline D(LOGEXGDP) & 0.056319 & 4.021499 & 0.0276 \\
\hline D(LOGIMGDP) & -0.090021 & -5.462383 & 0.0121 \\
\hline $\mathrm{C}$ & 0.663516 & 2.469417 & 0.0901 \\
\hline \multicolumn{4}{|c|}{ Bağımlı Deği.: LOGEOI-TÜRKIYYE } \\
\hline $\begin{array}{c}\text { Deği. } \\
\text { CointEq (-1) }\end{array}$ & $\begin{array}{c}\text { Kats. } \\
-0.283977\end{array}$ & $\begin{array}{c}\mathrm{t} \text {-is. } \\
-22.02686\end{array}$ & $\begin{array}{c}\text { Ola. De. } \\
0.0002\end{array}$ \\
\hline
\end{tabular}




\begin{tabular}{|c|c|c|c|}
\hline D(LOGEXGDP) & 0.104706 & 11.10406 & 0.0016 \\
\hline D(LOGIMGDP) & -0.008318 & -1.017433 & 0.3839 \\
\hline $\mathrm{C}$ & 0.899725 & 6.982568 & 0.0060 \\
\hline \multicolumn{4}{|c|}{ Bağımlı Deği.: LOGEOI-BİRLEŞİK KRALLIK } \\
\hline Deği. & Kats. & t-is. & Ol. De. \\
\hline CointEq $(-1)$ & -0.024853 & -4.247844 & 0.0239 \\
\hline D(LOGEXGDP) & -0.112271 & -5.896553 & 0.0097 \\
\hline D(LOGIMGDP) & 0.086065 & 3.715087 & 0.0339 \\
\hline $\mathrm{C}$ & 0.084127 & 1.254878 & 0.2984 \\
\hline \multicolumn{4}{|c|}{ Bağımlı Deği.: LOGEOI-ABD } \\
\hline Deği. & Kats. & t-is. & O1. De. \\
\hline CointEq $(-1)$ & -0.164618 & -22.31731 & 0.0002 \\
\hline D(LOGEXGDP) & -0.113616 & -17.85777 & 0.0004 \\
\hline D(LOGIMGDP) & 0.029352 & 6.613082 & 0.0070 \\
\hline $\mathrm{C}$ & 0.581640 & 6.247836 & 0.0083 \\
\hline \multicolumn{4}{|c|}{ Bağımlı Deği.: LOGEOI-AVUSTRALYA } \\
\hline Deği. & Kats. & t-is. & Ol. De. \\
\hline CointEq $(-1)$ & -0.131526 & -61.17854 & 0.0000 \\
\hline D(LOGEXGDP) & 0.040252 & 82.23393 & 0.0000 \\
\hline D(LOGIMGDP) & -0.034323 & -17.51250 & 0.0004 \\
\hline $\mathrm{C}$ & 0.464378 & 17.57624 & 0.0004 \\
\hline \multicolumn{4}{|c|}{ Bağımlı Deği.: LOGEOI-ÇEK CUMHURIYYETİ } \\
\hline Deği. & Kats. & t-is. & Ol. De. \\
\hline CointEq $(-1)$ & -0.164434 & -17.06343 & 0.0004 \\
\hline D(LOGEXGDP) & 0.003816 & 0.120650 & 0.9116 \\
\hline D(LOGIMGDP) & -0.037202 & -1.256872 & 0.2978 \\
\hline $\mathrm{C}$ & 0.511872 & 5.518869 & 0.0117 \\
\hline \multicolumn{4}{|c|}{ Bağımlı Deği.: LOGEOI-FINNLANDIYYA } \\
\hline Deği. & Kats. & t-is. & Ol. De. \\
\hline CointEq $(-1)$ & -0.029525 & -1.125776 & 0.3422 \\
\hline D(LOGEXGDP) & 0.264641 & 5.268905 & 0.0133 \\
\hline D(LOGIMGDP) & -0.306934 & -8.096959 & 0.0039 \\
\hline $\mathrm{C}$ & 0.106789 & 0.381054 & 0.7285 \\
\hline \multicolumn{4}{|c|}{ Bağımlı Deği.: LOGEOI-MACARİSTAN } \\
\hline Deği. & Kats. & t-is. & Ol. De. \\
\hline CointEq $(-1)$ & -0.741017 & -53.00294 & 0.0000 \\
\hline D(LOGEXGDP) & 0.177243 & 10.30570 & 0.0019 \\
\hline D(LOGIMGDP) & -0.312584 & -16.01213 & 0.0005 \\
\hline $\mathrm{C}$ & 2.202506 & 17.26620 & 0.0004 \\
\hline \multicolumn{4}{|c|}{ Bağımlı Deği.: LOGEOI-JAPONYA } \\
\hline Deği. & Kats. & t-is. & Ol. De. \\
\hline CointEq $(-1)$ & -0.135533 & -20.71243 & 0.0002 \\
\hline D(LOGEXGDP) & -0.048795 & -3.740556 & 0.0333 \\
\hline D(LOGIMGDP) & 0.059699 & 5.591147 & 0.0113 \\
\hline $\mathrm{C}$ & 0.478883 & 5.753702 & 0.0104 \\
\hline \multicolumn{4}{|c|}{ Bağımlı Deği.: LOGEOI-MEKSİKA } \\
\hline Deği. & Kats. & t-is. & Ol. De. \\
\hline CointEq $(-1)$ & -0.139193 & -6.708449 & 0.0068 \\
\hline D(LOGEXGDP) & 0.433792 & 7.864753 & 0.0043 \\
\hline D(LOGIMGDP) & -0.413185 & -6.975711 & 0.0060 \\
\hline $\mathrm{C}$ & 0.446923 & 2.117683 & 0.1245 \\
\hline \multicolumn{4}{|c|}{ Bağımlı Deği.: LOGEOI-YENİ ZELANDA } \\
\hline Değ & Kats. & t-is. & Ol. \\
\hline
\end{tabular}




\begin{tabular}{|c|c|c|c|}
\hline CointEq $(-1)$ & -0.092722 & -6.954064 & 0.0061 \\
\hline D(LOGEXGDP) & -0.060411 & -12.71406 & 0.0010 \\
\hline D(LOGIMGDP) & 0.014753 & 3.276804 & 0.0465 \\
\hline $\mathrm{C}$ & 0.323312 & 2.030712 & 0.1353 \\
\hline \multicolumn{4}{|c|}{ Bağımlı Deği.: LOGEOI-POLONYA } \\
\hline Deği. & Kats. & t-is. & Ol. De. \\
\hline CointEq $(-1)$ & -0.172642 & -9.792747 & 0.0023 \\
\hline D(LOGEXGDP) & 0.060424 & 1.705361 & 0.1867 \\
\hline D(LOGIMGDP) & -0.101730 & -5.402274 & 0.0124 \\
\hline $\mathrm{C}$ & 0.540611 & 3.245331 & 0.0477 \\
\hline \multicolumn{4}{|c|}{ Bağımlı Deği.: LOGEOI-SLOVAKYA } \\
\hline Deği. & Kats. & t-is. & Ol. De. \\
\hline CointEq (-1) & -0.121162 & -17.79463 & 0.0004 \\
\hline D(LOGEXGDP) & -0.490055 & -29.96141 & 0.0001 \\
\hline D(LOGIMGDP) & 0.597921 & 35.64489 & 0.0000 \\
\hline $\mathrm{C}$ & 0.363539 & 6.257176 & 0.0082 \\
\hline \multicolumn{4}{|c|}{ Bağımlı Deği.: LOGEOI-GÜNEY KORE } \\
\hline Deği. & Kats. & t-is. & Ol. De. \\
\hline CointEq (-1) & -0.102065 & -30.34556 & 0.0001 \\
\hline D(LOGEXGDP) & 0.113601 & 51.00238 & 0.0000 \\
\hline D(LOGIMGDP) & -0.084319 & -28.19151 & 0.0001 \\
\hline $\mathrm{C}$ & 0.329097 & 9.257881 & 0.0027 \\
\hline \multicolumn{4}{|c|}{ Bağımlı Deği.: LOGEOI-ŞİLİ } \\
\hline Deği. & Kats. & t-is. & Ol. De. \\
\hline CointEq $(-1)$ & -0.244272 & -28.12173 & 0.0001 \\
\hline D(LOGEXGDP) & 0.018461 & 8.622563 & 0.0033 \\
\hline D(LOGIMGDP) & -0.029180 & -20.13898 & 0.0003 \\
\hline $\mathrm{C}$ & 0.831406 & 8.211086 & 0.0038 \\
\hline \multicolumn{4}{|c|}{ Bağımlı Deği.: LOGEOI-ESTONYA } \\
\hline Deği. & Kats. & t-is. & Ol. De. \\
\hline CointEq $(-1)$ & -0.299387 & -40.09972 & 0.0000 \\
\hline D(LOGEXGDP) & 0.088116 & 5.216858 & 0.0137 \\
\hline D(LOGIMGDP) & -0.102490 & -8.106143 & 0.0039 \\
\hline $\mathrm{C}$ & 0.934556 & 12.72837 & 0.0010 \\
\hline \multicolumn{4}{|c|}{ Bağımlı Deği.: LOGEOI-SLOVENYA } \\
\hline Deği. & Kats. & t-is. & Ol. De. \\
\hline CointEq (-1) & -0.639798 & -23.61525 & 0.0002 \\
\hline D(LOGEXGDP) & -0.072052 & -0.896627 & 0.4360 \\
\hline D(LOGIMGDP) & -0.086830 & -1.298813 & 0.2848 \\
\hline $\mathrm{C}$ & 1.892194 & 8.010039 & 0.0041 \\
\hline \multicolumn{4}{|c|}{ Bağımlı Deği.: LOGEOI-İSRAİL } \\
\hline Deği. & Kats. & t-is. & Ol. De. \\
\hline CointEq (-1) & -0.109616 & -16.78155 & 0.0005 \\
\hline D(LOGEXGDP) & -0.168430 & -7.509419 & 0.0049 \\
\hline D(LOGIMGDP) & 0.022250 & 1.372971 & 0.2634 \\
\hline $\mathrm{C}$ & 0.356477 & 5.333741 & 0.0129 \\
\hline
\end{tabular}

\section{ETIKK ve BİLIMSEL İLKELER SORUMLULUK BEYANI}

$\mathrm{Bu}$ çalışmanın tüm hazırlanma süreçlerinde etik kurallara ve bilimsel atıf gösterme ilkelerine riayet edildiğini yazar(lar) beyan eder. Aksi bir durumun tespiti halinde Afyon Kocatepe Üniversitesi Sosyal Bilimler Dergisi'nin hiçbir sorumluluğu olmayıp, tüm sorumluluk makale yazarlarına aittir 